\title{
Effects of firm presence in customer-owned touch points: A self- determination perspective
}

\author{
Ali Yakhlef, Fredrik Nordin \\ Stockholm Business School, Stockholm University, Sweden
}

\section{A R T I C L E I N F O}

\section{Keywords:}

Customer-owned touch points

Customer engagement

Customer experience

Self-determination theory

\begin{abstract}
A B S T R A C T
Customer-owned touch points have emerged as a central context for customers to consume, contribute, and create content while interacting with one another on social media. Research on how firms' attempts to intervene in such forums affect customers' experience supremacy is still in its infancy. This study attempts to address this limitation, suggesting a framework for understanding firms' impact on customer experience in customer-owned forums. Towards this aim, we adopt self-determination theory as a theoretical lens, and, empirically draw on interview material gleaned from customer-owned touch point users. The results show that companies' attempt to control the discussions in such forums may have a negative impact on customers' experiences when it undermines their sense of autonomy, relatedness, and competence. However, firms' intervention is welcome when the intention is to add value, enabling customers to retain or enhance their feeling of self-efficacy and social esteem.
\end{abstract}

\section{Introduction}

Recent advances in technology, most notably the emergence of social media, have given rise to new touch points between customers and firms (Anderl, Schumann, \& Kunz, 2016), that tend to lie outside firms' direct control (Lemon \& Verhoef, 2016). Such touch points, initiated, designed, and managed by customers themselves (Lemon \& Verhoef, 2016; Anderl et al., 2016), constitute an increasingly important part of the customer experience journey. Thanks to social media, customers can now interact through these touch points. For instance, IKEA Hackers community is a context within which customers share online their experiences with peer customers and independent information sources (Baxendale, Macdonald, \& Wilson, 2015; Lemon \& Verhoef, 2016). In this context, customers interact with one another and share experiences and knowledge, exchanging advice relying on electronic word of mouth (Krishen, Berezan, Agarwal, \& Kachroo, 2016). While such interactions can significantly influence the customer's experience and perception of the company and the brand, it is difficult for the company to control them. Given that customer experience is critical for companies, the emergence of these online platforms for social interaction and networking which lie outside the control of companies poses a challenge for them to manage and control customer experience across all the touch points that define the customer journey (Lemon \& Verhoef, 2016).

A considerable body of research has addressed the factors that affect customer experience within firm-controlled touch points, the ultimate aim being to understand the process of managing it (Flavián, Ibáñez-Sánchez, \&
Orús, 2019; Liu, Shin, \& Burns, in press). However, there is hardly any research into how customer-owned touch points should or should not be interfered with, let alone managed, by firms. Researchers have been quick to caution that customer-owned touch points are to be approached carefully, if at all, by firms, as firms' attempts to control or interfere in these sites may not be viewed by the customers as legitimate (Fournier \& Lee, 2009; Krishen et al., 2016). Because, as Krishen et al. (2016) point out, social media sites that do not meet users' needs for relatedness, competency, and autonomy may lose these users. This thinking is premised on the assumption that social media, somewhat in contrast to business media, can have significant psychological effects on its users through influencing their sense of being self-dependent and self-efficacious. These effects can shape customers' degree of engagement (e.g., Hansen \& Levin, 2016; Krishen et al., 2016), assuming that firms have an effect on consumers' social networking motivation. Although Krishen et al. (2016) assume that consumers' engagement is affected by the extent to which consumers' self-determination is promoted or frustrated, they gloss over how firms' attempts at controlling or interfering in customer-owned touch points are perceived by customers and what effect it would have on their engagement and customer experience. The way in which firms interfere is crucial, for if carried out in the wrong way, it could lead to a bad customer experience.

Therefore, it is the aim of the present study to examine customers' perceptions of firms' attempts to exert influence on their experiences in touch points they consider as their own. Theoretically, the study is guided by the assumption that firms' intervention may challenge

\footnotetext{
* Corresponding author.

E-mail addresses: aya@sbs.su.se (A. Yakhlef), fn@sbs.su.se (F. Nordin).
} 
customers' feeling of being self-determining, self-efficacious and causal agents, which are basic psychological needs (Deci \& Ryan, 1985; Ryan \& Deci, 2002). However, intervention, if performed appropriately, can boost customers' engagement and amplify their experience of the firm, its products, services or brand. The research question of this paper then becomes: How and when does firms' intervention in customer-owned touch points affect customer experience in a positive and when it affects it in a negative way? In answering this question, we empirically draw on material gleaned from in-depth interviews with a number of customers who are active on customer-owned touch points.

The paper proceeds in the following way. Next section is devoted to showing the significance of managing customer experience for firms, at the same time suggesting that such attempts at controlling customers' experience in their own touch points may not always be appreciated by customers, running the risk of impeding their urge to being self-serving and feeling autonomously motivated to participate in these forums. Therefore, self-determination theory (e.g., Ryan \& Deci, 2002) is deemed a relevant theoretical pre-understanding for framing and interpreting the empirical material to be used in this study. In section 3 , we briefly present the method adopted. In section 4 , we deductively use self-determination theory and inductively make use of our empirical insights to further the understanding of customers' perceptions of firms' attempts to interfere in discussions taking place in their touch points with a view to impacting their experience. Finally, in section 5, conclusions, implications and suggestions for future studies are suggested.

\section{Theoretical background}

\subsection{Managing customer experience in a social context}

Traditionally, customer experience has been viewed as the outcome of customers' interactions with firms at touch points largely owned by the firms, including advertising, physical stores, and websites (Lemon \& Verhoef, 2016). However, following from recent developments in technology, several touch points have come to lie outside firms' direct control. This loss of control by firms over some of the factors that shape customer experience is a source of concern for marketing managers. Touch point experiences can vary in intensity and time based on one-way and two-way communication between customers and firms but can also be co-created through customer-to-customer interactions, occurring via social media and peer-to-peer communication (Prahalad \& Ramaswamy, 2004; Lemon \& Verhoef, 2016). A touch point can thus be understood as a point of interaction between a customer and a company or a brand which may also include interaction between different customers focusing on the company or the brand. Anderl et al. (2016) have developed a taxonomy of the different touch points in the online channel context separating what they call firminitiated touch points from customer-initiated ones. They define firm-initiated touch points as those that are managed by either the firm or one of its partners. As for customer-initiated and -owned touch points, these are managed by customers themselves (Anderl et al., 2016), thus, lying outside firms' control (Lemon \& Verhoef, 2016). Examples of this type of touch points involve instances where customers join forces in the pre-purchase phase (Puccinelli et al., 2009) or during the post-purchase phase, to share information on how to consume a given product and to share their views regarding their consumption experience (Lemon \& Verhoef, 2016). These customer-owned touch points, which are initiated, designed and managed by customers, are posed to have a greater effect on customer experience than traditional marketing activities (Baxendale et al., 2015).

In this way, social media are set to challenge the way customer experience is shaped and managed. For instance, in traditional brickand-mortar settings, customer experience can be shaped by visual, olfactory and sonic factors. Within service marketing, great care is taken to manage the interaction between the service employee and the customer with a view to creating satisfactory, positive experiences (Bitner, Booms, \& Tetreault, 1990). These factors, designed by the firms to more or less control the experience may hold when a customer enters a store
- a touch point which is owned by the firm - but what happens when customers turn to touch points that are not under the firm's direct control (Lemon \& Verhoef, 2016)?

Advances in technology have transformed the customer journey, making it more social in structure, and more complex in nature (Lemon \& Verhoef, 2016). In this social environment, online customers can share their experiences and ratings on review sites such as Yelp, Google + and TripAdvisor, among many others, as well as in virtual communities initiated by customers who are joined by shared interests, e.g. IKEAhackers, as mentioned before. Such forums can enhance customer experience but can also negatively shape pre-conceptions based on others' experiences (Hagel, 1999; Kim \& Jin, 2006; Verhoef et al., 2009). Therefore, touch points of this character should be approached carefully by firms, as the focus is on customers' perceptions of firms' products or brands and their interests - a process mainly driven by intrinsic motivation and social dynamics. How do customers perceive firms' attempts at influencing discussions in such forums? How and when should firms become involved in such forums, knowing that any false-maneuver, or undue manipulation or attempts to control the discussions can be perceived negatively by customers and may have counter-effects on customer experience? Extant theories have not caught up yet with these new challenges arising from the multiplicity of touch points (Lemon \& Verhoef, 2016). For instance, Lemon and Verhoef (2016) call for more research into how firms can exert more control over touch points not "owned" by firms. Firms are thus left facing a dilemma: while access to and control of customer-owned touch points can be valuable for creating a positive experience, any such false move or attempt to control them may lead to undesirable results (e.g., Fournier \& Lee, 2009). Thus the present paper addresses the question of how customers perceive firms' interventional behaviors in touch points considered by customers as their own. How are different firm behaviors, aiming to control or influence discussions occurring in customer-owned touch points, perceived by customers and what are their effects on customer experience?

Social media, as the designation connotes, are, in contrast to business or private media, first and foremost social arenas for consumer socialization. They provide a new interaction and socialization paradigm. Socialization is articulated through two forms of influence: informational and normative (Deutsch \& Gerard, 1955). Informational social influence is a tendency to accept information from other peer consumers as evidence and facts representing 'reality'. This is probably why learning and gaining advice from peers are recognized as more genuine and trusted, as peers are not motivated by profits, in contrast to information stemming from firms and marketers which may have the intention to affect, for instance, consumers' purchase decision. It is in this context that the concept of electronic word of mouth (eWOM) has gained popularity. Normative social influence is related to members' willingness to develop their own normative rules and values, to preserve the cohesiveness and the moral support of the group members. In sum, whereas informational social influence enables members to acquire information that reduces uncertainty regarding their purchase decisions, the normative aspect serves to foster a social context that offers its members social support and relatedness. The informational and normative dimensions of social media enhance members' self-esteem and sense of self-efficacy (Naslund et al., 2017). Given this emphasis on the sociality of social media, we pose the question of what are the chances and prospects for firms to influence consumers' informational and normative processes?

\subsection{Self-determination theory and supremacy experience}

The line of thinking presented above brought to mind self-determination theory (e.g., Deci \& Ryan, 1985; Ryan \& Deci, 2002) which is a motivation theory that stipulates that people tend to be reluctant to attempts that may reduce their mastery experience, and impede the possibilities of exercising control over their life conditions. Self-determination theory is a theory that attempts to explain how and why people engage in certain kinds of behaviors and activities and how this 
affects their engagement, performance, and well-being. The basic idea of this theory is that people by nature are proactive and developmentoriented creatures whose intrinsic motivation and pursuit of self-efficacy can be stimulated (or hindered) by the extent to which their intrinsic psychological needs of competence, autonomy and relatedness are satisfied (or frustrated). Self-determination theory accounts for people's motivation behind the choices they make without external influences and interference. It seeks to explain the extent to which an individual's behavior, course of action, or experience, is self-motivated and (intrinsically) self-determined or whether it is (extrinsically) affected by external factors. Intrinsically driven behavior is self-initiated, often carried out for its own sake, based on an individual's personally internalized predispositions, past experiences, and values. Ryan and Deci (2002) proposed three intrinsic needs involved in self-determination: autonomy, competence, and social relatedness.

Etymologically, the term 'autonomy' means "self-rule". It literally refers to an individual's ability to govern him or herself, enjoying a sense of willingness, endorsement or volition in what one undertakes (Ryan \& Deci, 2017). However, autonomy does not have to be confused with merely acting independently and being in full control of oneself and of the circumstances that impact upon oneself; rather acting autonomously means acting willingly and in ways that concord with their personal objectives and values, making autonomy, meaningfulness, and purposefulness closely linked. Autonomy relates to the universal urge to be perceived as a causal agent of one's own life, without implying that people are completely independent of others. A feeling of being in control of one's self produces a deeper engagement in the activity one is pursuing, leading to a positive experience.

Competence has to do with a person's need for exerting mastery and control over one's experience with confidence and self-efficacy. The feeling of being competent is shaped by one's perceived self-efficacy beliefs. Perceived self-efficacy involves an individual's beliefs about their capabilities to exert influence over events that shape their lives (Bandura, 1993), the ability and capacity to accomplish a particular task autonomously. Self-efficacy beliefs play a pivotal role as they affect how individuals feel, think, experience the world, and intrinsically motivate their behavior.

Whereas autonomy and competence are intra-psychic processes concerning intra-personal growth and development, relatedness pertains to their relations to the social world and the need for harmonious social integration. This need for relatedness energizes exploration and interaction with others. Social relatedness pertains to humans' universal want to relate to others, to interact, to be connected to, experience caring for, and being cared for by others. It is also related to incorporation and internalization of various forms of information and knowledge, values and norms that happen to prevail in a given social system. It revolves around the feeling of belonging, of being secure, connected to, or understood by, and in tune with others (Grolnick \& Ryan, 1989).

In sum, autonomy, competence, and social relatedness are the nutriments that are crucial for a sense of self-determination, as they define the conditions that are conducive to a positive experience. Positive experience emanates from individuals' fulfillment of their psychological needs. These conditions, if they satisfy, rather than frustrate, individuals' basic needs for autonomy, competence and relatedness lead to flourishing, and personal development (Peters, Calvo, \& Ryan, 2018).

\subsection{Self-determination supportive customer experience}

By understanding the underpinnings underlying self-determined behaviors, it is possible to appreciate the important role played by the social context in supporting or inhibiting autonomous experience. A focus on how autonomy, competence, and relatedness energize intrinsic motivation may point the way to the nutriments of self-determination, and how they can be supported by external factors, including the behavior of firms in customer-owned touch points. For as noted above, autonomy does not mean freedom from environmental influence. Rather the opposite, the social context through subtle intervention plays a significant role in promoting or thwarting the feeling of selfdetermination. Several researchers (such as Grolnick \& Ryan, 1989) have submitted that external interventions that provide options and choices for an individual, that do not require actions from them without their consent, and that afford them a sense of ownership are likely to enhance feelings of self-determination.

Grolnick and Ryan (1989) identify three nutriments that support self-determination: (1) encouraging self-initiation, allowing independent problem solving, and minimizing control and power assertion; (2) providing a structure so as to guide and offer a coherent field of operations, administering feedback and guidance; and (3) being involved by devoting time, attention and resources to the individuals as they explore new territories and express themselves. Research also indicates that exploring the counterpart's concerns, providing choices and acknowledging feelings contribute to the feeling of self-determination, by endorsing their social bonding and relatedness (Deci, Eghrari, \& Leone, 1994; Markland, Ryan, Tobin, \& Rollnick, 2005). Positive feedback and clear but neutral guidance regarding agentic activity will tend to nurture the perception of competence (Markland et al., 2005). Getting involved and devoting time and attention by listening and providing resources indicate that the intervening agent cares about the activities of the individuals under consideration. Paying attention to what individuals are doing and listening to what they say enhance their need for self-expression. In contrast, persistent, negative feedback and attempts to influence and control may be perceived as a sign of incompetence and deficient self-efficacy, thereby reducing self-determination (Deci \& Ryan, 2000).

We assume that similar relationships exist between firms' behavior in customer-owned touch points and the sense of self-determination of the customers who are active there. It is deemed that empirical study is necessary to amplify and lend support to these theoretically based and preliminary ideas and to provide more nuanced answers to our questions. Accordingly, these theoretical considerations will be used as a lens to understand customers' perceptions and effects of firms' interventions in these contexts and as a springboard for tentatively developing a framework. Before that, a word on method is in order.

\section{Method}

The literature review prompted an interest in and a need for more in-depth knowledge of the motives that drive customers engaged in what they consider their own touch points and how firms' efforts to interfere with or exert control over their interactions in such touch points affect their experience. Using existing literature on self-determination and its connection to motivation, specifically regarding engagement in social media, we first developed a tentative framework that we subsequently evaluated and specified based on a body of interview material. More specifically, with our theoretical background as a starting point, we tried to deepen our understanding of the motives behind customer engagement in customer-owned touch points and how different involvement by companies in discussions taking place in these forums may affect customer experience. As noted above, we made use of semi-structured interviews with people who were active in various customer-owned forums on Facebook, so called Facebook Groups. ${ }^{1}$

A Facebook Group is "a place to communicate about shared interests with certain people" (Facebook.com, 2019), which can be created by anyone for virtually anything. Similar groups can be found on LinkedIn and YouTube, for instance, but the reason we chose Facebook was because it is one of the most used and popular platforms for communication among like-minded individuals. In this sense, it can be

\footnotetext{
${ }^{1}$ We are thankful to our former master's student Tea Dahlgren for helping us with the data collection task.
} 
Table 1

Respondent descriptions.

\begin{tabular}{|c|c|c|c|c|}
\hline Pseudonym & Gender & Age & Occupation & Fora \\
\hline Abbie & Female & 26 & Skill Lead within Conversion Optimization & Foods, Software, Stock-deals, Fashion \\
\hline Bennet & Male & 37 & Self-employed within the rental business & Asthma and Allergies, Fitness, Foods \\
\hline Clark & Male & 47 & Self-employed animator & Photography, Software \\
\hline David & Male & 25 & Pilot & Cycling \\
\hline Edna & Female & 28 & Account Manager within PR & Stock-deals, PR, Advertisement \\
\hline Faron & Male & 34 & Supply Chain Manager & Foods, Gardening \\
\hline Gaby & Female & 27 & Content Specialist & Wedding, Plants \\
\hline
\end{tabular}

regarded as a relatively representative research site (Yin, 1994) of the phenomenon we are interested in. In line with our aim, we chose to focus on Facebook groups that were created and run by people other than representatives of specific companies. Companies can also create Facebook groups for their respective companies and their products, but, in consistency with our purpose, we instead opted for self-created groups that focused on different areas of interest, such as cycling or health, in which particular companies and their specific products were often discussed, reviewed and assessed. We did not select any specific Facebook group, but instead discussed the phenomenon with different individuals, focusing on their experiences and perceptions of being part of such Facebook groups. This allowed us to gain insights into a more extensive material depicting their thoughts and experience of different groups where customers were interacting with one another and where representatives of companies may also participate in these groups to different degrees and in different ways. This said, our aim is not to seek statistic generalization, but rather, theoretical generalization (Yin, 1994). For, although our study draws on a single case of Facebook Groups, it consists of several embedded cases in the form of different customer-owned touch points.

Since our aim was to glean insights from users of customer-owned touch points rather than testing pre-set hypotheses, we adopted a judgment sample of respondents (cf. Marshall, 1996). We have striven to achieve a good spread among ages, gender, and orientation in the Facebook groups in which the respondents were active (see Table 1). Most respondents had experience of more than one Facebook group forum and all of them were experienced users of this kind of forums. All of which meant that they were able to relate to the phenomenon at large and not just to the specific Facebook group.

To find out about the respondents' perceptions, lived experiences and motives behind their engagement in these forums, we kept the interviews relatively open, allowing the respondents to freely share their concrete real-life experiences and motives related to their engagement (cf. Seale \& Silverman, 1997). The interview questions were often followed up with "why" and "can you develop" questions to get more specific details. Although open-ended, the interview guide helped us maintain a certain focus and structure.

During the analysis phase, we started off by reading the transcribed interviews several times, to reach an overall picture of, and to familiarize ourselves with the entire set of data. Then, during the deductive qualitative analysis (Gilgun, 2005), both authors analyzed the material with the theoretical background as a pre-understanding. The purpose of the analysis was to answer the research questions and to illustrate and refine (Keating, 1995) the preliminary ideas we had developed based on the literature and previous research. Respondents' statements were grouped into major interpretive themes that conveyed expressions of firms' intervention techniques and interviewees' perceptions of these attempts. During the analysis, we tried not to force the results to fit our initial thoughts by systematically questioning each other's interpretations and confront them with extant theory. We focused on drawing logical and theoretically sound conclusions, not just empirically robust conclusions. The theoretical background helped us in this regard, but we also enfolded additional literature during the analysis phase to reinforce our arguments and conclusions (cf. Eisenhardt, 1989) and to further develop the results. In the inductive stage, we used insights from the elicited material to buttress and enrich the initially theoretically driven framework, developing it into a more contextualized one. The overall aim was to set the grounds for a framework of the phenomenon under consideration, hopefully triggering off other researchers' interest in testing and developing the present framework in different contexts.

\section{Emerging themes}

Social media have enabled customers to become more active in seeking and exchanging information, in having a say in what they consume, and creating and contributing content. This form of consumer empowerment (Cova \& Pace, 2006) is all the more important as one of the crucial features of social media is the opportunity to enable consumers to foster and strengthen relationships with peers, sharing interests in a space they consider as their 'comfort zone', since it is initiated, created, and owned by themselves. In these spaces, consumers assume various forms of engagement depending on the degree of activism and motivation animating them. In the main, these range from lurking, socializing, getting connected, etc., to creating and consuming content generated by themselves (see Bernoff \& Li, 2008). Not only do these consumer-to-consumer interactions define the degree of engagement with firms' products, services or their brands and participation in the discussions that take place there but they also shape their customer experience.

\subsection{Social motives behind participating in customer-owned touch points}

What drives consumers to engage in these networking sites, according to previous research, is the need for affiliation and social identity (Boyd \& Ellison, 2007). Consistent with this line of thinking, our respondents stated that the main reason why they engage with customer-owned touch points is the need to interact with like-minded peers, ones to whom they can relate. As pointed out by Baxendale et al. (2015), our respondents generally engaged in customer-owned touch points to find inspiration, advice, and information that reduce uncertainties regarding their consumption behaviors. They were looking for recommendations from other customers in a peer-topeer trust-based environment. These touch points were perceived as being owned and managed by the customers themselves, as two of our respondents described them as: "...somewhat self-regulated" (Clark), where "you seek other people's opinions, look for some advice or tips regarding things, or find inspiration. It becomes like a group of friends in some way" (Gaby). Another respondent emphasized the higher credibility of other customers compared to companies: "Firms want to make profits, but my friend or any acquaintance just means well" (David). In a similar vein, another respondent noted the difference between trusting peers and trusting firms:

"When I discuss brands, I want to do that with my peer-consumers because I trust the stories they tell. Being well aware that firms are ultimately interested in selling what they offer, I trust more somebody who does not want me to buy anything" (Abbie).

The same respondent also stressed that customer forums may be more fun to visit, which is also the reason they are popular: "the aim 
here is to help and inspire one another. You throw a question and everyone is committed to respond, investigate and explore". Another respondent said that unlike in firm-owned touch points, "which are driven by marketing purposes, a customer-owned forum is more open, because you meet a larger group of people who share the same culture and lifestyle; it's much more open and more fun. You get multiple perspectives on what is happening, not just the firm's perspective" (Faron). This is why over time, such a community becomes "like a group of friends in some way", added another respondent (Gaby).

A respondent who was active on both firm-owned and customerowned forums discerned the following difference:

"In customer-owned communities, people scrutinize and evaluate more critically what is posted, especially when claims are not clear or wrong. People are freer to express themselves. Therefore, I find the customer-owned forum to be 'livelier'... animated by new questions every hour of the day" (Clark).

Along similar lines, in describing the differences between firmowned and customer-owned touch points, two respondents made the following statements: "It's a little harsher climate in the customerowned forums. They can be very critical vis-á-vis firms and the things that are wrong or statements biased toward products that do not meet expectations" (Clark) whereas "firm-owned forums get very oriented towards specific marketing purposes" (Faron).

\subsection{Customer-owned touch points are perceived as self-regulated}

In the absence of firms, the touch points are perceived as being managed by the customers themselves. As noted above, some respondents experienced the forums as self-regulated. Other respondents noted that some customer-owned groups are self-managed, with some customers functioning as administrators in control over the content, e.g.:

"If one misbehaves, one can get warnings and such things. If it happens again, you're suspended... I wouldn't say that happens often because there are very clear guidelines that you have to comply with" (Bennet).

Although such guidelines often include rules against promoting products and advertisement there are "people who are not always very disciplined. I guess all administrators are struggling to get their members to behave according to the rules" (Gaby). Aside from the explicit guidelines within the forum, there is some kind of implicit control: "You don't want to ask a stupid question or post a strange comment because it might affect your reputation" (Edna). Social self-esteem is an important control mechanism whereby consumers' control themselves by themselves. In this sense, customer-owned touch points have the advantage of providing secure zones for the participants to socialize unfettered by firms' intervention. This gives them a feeling of ownership of their experience, that they are self-determining and autonomous (cf. Ryan \& Deci, 2002) with regard to their opinion, judgement, critique, and action. Although the respondents insisted on the self-regulated, self-controlling nature of customer-owned touch points they nevertheless did not utterly dismiss the presence of firms.

\subsection{The perils and promises of firms' presence in customer-owned touch points}

Customers' aspirations for independence and self-regulation do not contradict their need for self-development and their urge to learn from other sources than themselves. It is in this context that our respondents recognized the fact that firms are also present in such forums and the role they play there. One respondent said:

"You can sense when someone is present as a representative of a firm, with an agenda, providing advice, and recommending the purchase of certain products. It may be well meant but you always know that the person does it deliberately to promote his or her employer" (Gaby).

Indeed, all the respondents were aware of the fact that firms are alive and active in the customer-owned touch points and that "they are involved, making brief comments here and there" (Abbie).

Generally, the respondents were reluctant to having firms in their environment because they feared that such intervention would threaten the very essence of customer-owned touch points and affect the sense of self-efficacy, of not being able to decide by themselves over what they want to exchange and discuss. One of our respondents emphasized that

"Firms should not even try to control these touch points. These touch points would lose their meaning if they are managed for the sake of profit: rather these are run as a collective of peer-to-peer consumers with no hidden motives than the fun of relating to other peer customers" (Abbie).

Another respondent added that there should not be any "external control. It applies to all communities initiated by consumers in general. That's the whole idea, it has to be living its own life. Otherwise, we are back to the old-school of marketing that teaches us: 'you should think and do like this'. It simply doesn't work like that in these contexts" (Clark). Overall, however, they said that most groups do not allow any corporate intervention in their forums and that only private consumers are allowed. It is stated that this "forum is not for corporations, therefore, posts that have some kind of connection to firms are removed. For example, I am a member of an allergy and asthma discussion group and personally sell air purifiers. One day I posted that I sell products that could be helpful. That post was immediately removed because it was perceived as an advertisement for my firm" (Bennet).

In spite of all, the respondents believed that there were benefits that they could derive from firms' presence, in particular, concerning questions related to specific features of products or brands. In such cases, they admitted that it might be good if someone from the firm could come in and say "This is how it is or how it works" (Clark). It is ok for firms to enlighten them on the matter, answering their questions and solving their problems. Hence, there seems to be a place for firms in customer-owned touch points. One respondent differentiated between two ways through which firms make themselves present in customerowned touch points: "making PR activities" or "adding value". He explained that the PR-way is when firms just say things like "thank you for saying that, we're so glad", or "we are really sorry this happened to you and we will try to do better next time" (Abbie). By contrast, he said that the value adding way can increase customers' stock of knowledge and improve their way of interacting with the product or the brand in a more engaging way. He explained: "There is a big difference between those two approaches ... you can tell by whether the person making comments upon customer reviews is from the PR department or is someone with actual product expertise" (Abbie). In line with this statement, another respondent elaborated:

"Firms are welcome to join the discussions and explain for us why certain things are the way they are, based on facts, and not getting emotionally involved in defending their products. It is OK when it can be informative, when someone from the firm who is truly knowledgeable, clarifies things for us" (Clark).

Following up on the previous point and much in consistence with the rationale for the emergence of customer-owned touch points, another respondent explained his view as follows:

"As long as the firm contributes with inspiration instead of some form of super-duper advertising stuff, and as long as they understand that these groups are there primarily to relate to one another and to learn more, it's fine. But if it becomes too much of just throwing products on your face, it is not interesting" (Edna). 


\section{Seconding this view, another respondent noted:}

"It's OK that they are present but I do not want them to comment upon everything. They can be present but without interfering too much or being directive. It is better if they listen to the feedback that is being given and then use it to improve their products and their own touch points. That would generate greater value than just responding to my comment”. (Abbie)

The respondent continued and explained that firms can "increase customers' trust if they actively and genuinely engage with consumers' concerns and solve their problems". For instance, firms are supposed to respond to feedback that requires their attention or constructive feedback, rather than providing criticism of what is shared among the members themselves. One respondent explained: "If I have a specific issue with the firm I can go to their Facebook page and have an open dialog with them (...) but they can stay away from the closed group when the individual hasn't complained and asked for the firms' views" (David).

Emphasizing the positive side of firms' being present in customerowned touch points, another respondent added that it may be acceptable that firms participate in these forums so that they learn more about what consumers want and need: "You do not want products to be created out of nothing, without any practical relevance to people's actual needs" (Clark). The respondent continued and explained that companies should be humble, be able to take criticism, and show that they are listening. They should refrain from attempting to control and from depicting too positive a picture of themselves and their products. Customers are thus positive to firms' participation in customer-owned touch points if they can increase customers' stock of knowledge and inspire them, because customers are there to learn new things. This line of thinking is consistent with a self-determining behavior, as amplified in the next section. Table 2 summarizes the positive and the negative sides of firms' interventions in customer-owned touch points.

\section{Discussion and concluding remarks}

What seems to emerge from both the theoretical pre-understanding and the empirical information is that, in general, external interference (such as firms' intervention in customer-owned touch points) affects people's sense of experiencing themselves as self-determining subjects, crowds out motivation and potentially leads to a negative customer experience. However, when such interference amplifies subjects' self-

Table 2

How customers perceive firms' interventions in customer-owned touch points.

Customers' perceptions of their touch points

- They consider them as opportunities to interact with other customers so as to develop bonds of friendship

- They are places where they feel in control of their experience, and as self-regulated and self-directed agents, interacting based on their own free choice and interests and values

- It is there where they can express themselves freely and critically assess firms' products and brands in a trust-based (friendly) environment

Customers perceive firms' interventions as negative when they

- attempt to affect the process whereby customers are focusing on building social bonds with one another

- do not respect customers' perspective, attempts to be directive, pressuring them towards accepting firms' perspective

- do not provide time and space for listening and understanding why customers are experiencing problems. Rather, they should listen and pay attention to customers.

Customers perceive firms' interventions as positive when they

- listen and pay attention to customers' problem and provide solutions

- try to understand why customers are experiencing problems

- provide skill-building and non-pressuring, informational advice and knowledge,

- acknowledge and tolerate criticism, avoiding negative feed-back using an informational language

- genuinely learn from customers' feedback and create new products and services

- support customers' pursuit of self-worth and self-efficacy determination, motivation is enhanced, impacting their engagement and their customer experience positively.

In order for their needs for autonomy to be satisfied, our data illustrate that customers must feel free to choose when to interact with firms directly (through their Facebook pages) and when to interact with their peers in their own forums. Because when in customer-owned touch points, they do not want to feel their ability to express themselves freely and independently thwarted. Consistent with self-determination theory, freedom of choice increases individuals' feeling of being in control of their situation, of acting autonomously and strengthens their intrinsic motivation to pursue their engagement in the activity under consideration. Customer touch points are regarded as customers' secure grounds for exerting mastery experience in a self-efficacious way. Consequently, firms' attempts to intervene with a view to shaping customer experience are negatively perceived by customers if they are not autonomy-, competence-, and relatedness- supporting. Efforts that tend to thwart customers' basic needs to be causal agents of what is going on in their touch points lead to a sense of disharmony with one's integrated self, lessen intrinsic motivation to engage in such touch points, impacting customer experience in a negative way.

Regarding the need for competence, consistent with self-determination theory, the respondents do not object to firms' presence in their touch points when their aim is to help them learn about their products and services and answer their questions. In similar fashion, the elicited empirical information shows that such behavior seems to support their sense of competence and to increase their stock of knowledge. Learning and the search for knowledge are two of the building blocks of selfdetermination theory. Learning is an inherent tendency toward growth, development and integrated functioning (Ryan \& Deci, 2002) of the self. In order for such needs to be satisfied and to realize their full potential, they have to be developed in their social environment. This is so because social relatedness offers a friendly and secure context for the acquisition of knowledge. In this process, feedback supplied in a humble and supporting way is crucial. Constructive feedback is an important input in the learning process, whereas persistent, negative feedback can be indicative of a lack of competence, resulting in a negative experience.

As regards the need for relatedness, our data illustrates that consumers expect firms to listen to them, and pay attention to what they say. Although social media have championed freedom of speech, providing a large part of people the opportunity to voice their opinion, listening has not been recognized to the same extent. Ample literature suggests that social support helps firms to achieve a deeper sense of community bonding (Miller \& Pole, 2010; Rains \& Keating, 2011). Listening, according to Crawford (2009), apart from supporting consumers' need for social affiliation, enables firms to analyze and better understand consumers' needs. It lies at the basis of the dynamic process of online attention and helps firms build a stronger relationship with users. Crawford (2009) suggests that social media, if they are to fulfill their full promise, require active listening subjects, not only speaking subjects. Andzulis, Panagopoulos, and Rapp (2012) add that the process of social listening enables firms to develop a closer relationship with their customers, boosts brand reputation and contributes to customer satisfaction. The concept of listening provides a common space (or a bridge) where power is suspended (at least temporarily), for neither party can explicitly exert power. Social media such as Facebook, Google plus, Twitter and YouTube provide firms with valuable opportunities to listen to both the positive and negative opinions regarding their products (Greaves, Ramirez-Cano, Millett, Darzi, \& Donaldson, 2013).

\subsection{Concluding remarks}

The aim of this paper was to investigate how and when firms' intervention in customer-owned touch points affects customer experience in a positive or a negative way. To the best of our knowledge, this study is the first attempt to use self-determination theory to understand how 


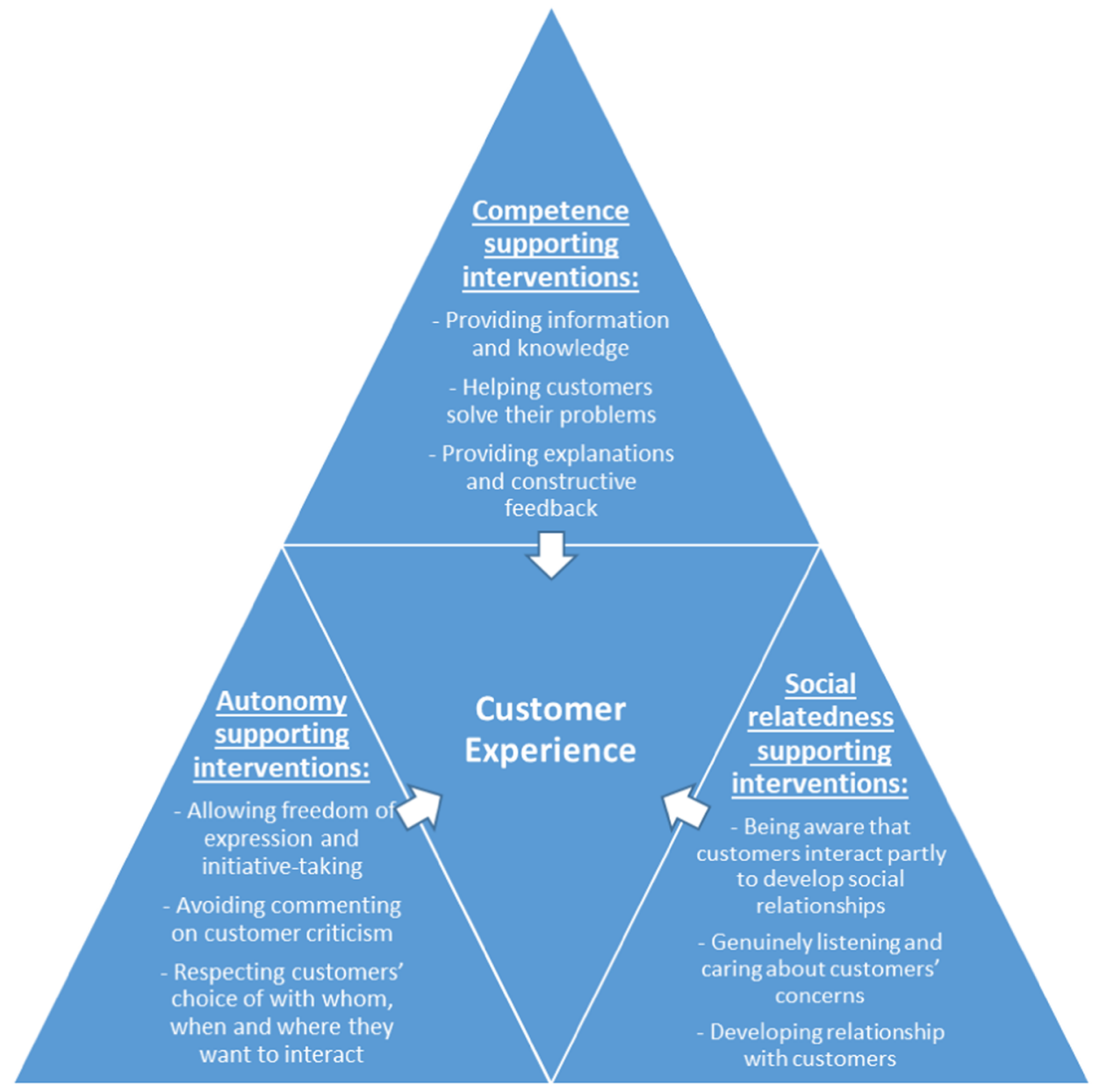

Fig. 1. Interventions that promote customers' self-determination.

firms' interference in customer-owned touch points may affect customers' sense of self-control over what they think, do and experience. Adapting and adopting concepts from self-determination theory and drawing on empirical insights, we have sought to develop a theoretical framework for understanding the factors that support or frustrate customers' engagement in their own touch points, which ultimately affect their customer experience positively or negatively, respectively.

Somewhat surprising was the point that customers were not categorically against firms intruding into their own space. Rather, it is the way firms behave in customer-own touch points that matters most. The first contribution of this paper consists in developing a framework of how firms' intervention in customer-owned touch points can lead to a negative experience when it frustrates basic needs for autonomy, competence, and social relatedness; and by contrast, how intervention that facilitates and supports the satisfaction of these needs stimulates their motivation to engage with the firm's products and brands, generating a positive experience. When satisfied, such needs help customers sustain their interest because they provide fuel for individuals' intrinsic motivation. The respondents emphasized the point that firms' help in solving problems is experienced positively as it enhances their self-efficacy. In like manner, providing positive feedback is also consistent with customers' search for self- determination. By contrast, authoritative, self-assertive replies and outright dismissal of customer criticism convey a message that customers are incompetent, lacking in self-efficacy, leading to a sense of unease and bad experience. Rather than "being all mouth", or having a loud voice in customer-owned forums, firms are more expected to lend an ear and listen to the various views and thoughts exchanged in such forums. When a firm listens, it means it pays attention to what is being said, which, in its turn, strengthens the two parties' social relationships. A second contribution of the paper is that it extends the narrow, economic, pragmatic interpretation assuming that customers trust more their peers because these are not trying to give them advice in exchange for economic profits (as captured in the phenomenon of eWOM), as is usually the case with firms' advice. Our study shows that the need to relate to others, to interact, to connect, and care and being cared for are hard-wired, human features that have an influence on how we experience the impact external forces seek to exert on us. In line with Krishen et al. (2016), our research suggests that customer-owned touch points can create a sense of community among members. This sense of community is only sustainable if the platform continues to meet the needs for autonomy, competence, and relatedness.

On an additional note, a third contribution of this paper is to shed light on von Hippel (1994) dilemma: the information about what the customer wants resides in the customer and the ability to satisfy those wants and needs lies within the firm (Thomke \& von Hippel, 2002). Whereas customers have problems related to what and how to consume, but do not have solutions to those problems, firms have solutions but do not know customers' problems. Listening in social media will enable firms to learn about what problems customers are tacitly facing, and from there it is only a short step to develop the appropriate solutions. From this perspective, the two parties can be viewed as in a complementary, interdependent relationship, rather than oppositional a point emphasized by our respondents.

The following figure (Fig. 1) presents our framework capturing firms' interventional behaviors that enhance customers' self-determination, the degree of motivation to engage in social forums and ultimately their experience. 
Furthermore, in these forums, discussions are carried out by customers when they engage with firms' brands, products of services in a reflective, deliberative way. Such moments of reflection may affect customer experience in the reflective mode, but it is not sure that these reflective moments play a central role in the moment of purchasing itself. Let us be reminded of the classical work of Underhill (1999) in which he describes supermarkets "as places of high impulse buying. Fully $60-70 \%$ of purchases there were unplanned" (p. 163). In this context, impulsive purchasing enables customers to experience not only "bodily warmth but also guilt" (Rook, 1987). Thus, given that customer experience is shaped by the various touch points that span the purchase journey, and given that customer-owned touch points are only one stage at which customer experience can be impacted upon, self-determination theory can explain customer experience in their reflective and not in their practical mode of engagement. If customer experience involves a customer's "cognitive, emotional, behavioral, sensory and social responses to a firm's offerings over the purchase journey" (Lemon \& Verhoef, 2016), self-determination theory captures the cognitive dimension of experience, thereby providing the beginning of an answer to Lemon and Verhoef (2016) question of how the different touch points affect customer experience. Self-determination theory sheds light on how customer experience may be affected in their own touch points and may be less so in other touch points.

\subsection{Managerial implications}

The present study has several practical implications. Among other things, it implies that firms need to approach customer-owned touch points with caution. This amounts to a shift from managing and controlling customers' experience towards caring, listening to and educating customers. Rather than adopting a pressuring interference and an authoritative and patronizing tone in the traditional 'we know what is best for you' way, firms' role becomes one of adding value through listening and providing information and knowledge that customers need, and paying attention to the ongoing discussion without unsolicited intervention. Implied is a move beyond the purpose of promoting products or services. The upshot is that firms are to change their attitude and behavior in social media, becoming highly responsive, vigilant and attentive.

\subsection{Future research}

Assuming that customer-owned forums are a context of evaluation, deliberation, and interpretation, they tend to revolve around customer's thinking and cognitive experience. Future research may further investigate how other perspectives (over and above self-determination theory with regard to the cognitive dimension of experience) may shed light on customer experience during the purchase phase, which is, as noted above, a phase susceptible to impulsive behavior and emotional arousal.

Although the results appear promising, they need to be confirmed, refined and expanded on by future research. A possible future direction is to explore the extent to which the results can be transferred to other touch points, even to forums that are firm-owned. At issue is whether the basic drivers behind the aspiration to be a self-determining, selfefficacious and self-related subject would not hold true even in other contexts, in spite of them being controlled by the firms.

In addition, and as noted above, customer-to-customer touch points constitute only one of the touch points that are available for firms. How much customer-owned touch points affect the whole customer experience is a question that lies beyond the remit of the present study but could be a topic for further investigation.

\section{References}

Anderl, E., Schumann, J. H., \& Kunz, W. (2016). Helping firms reduce complexity in multichannel online data: A new taxonomy-based approach for customer journeys. Journal of Retailing, 92(2), 185-203.

Andzulis, J. M., Panagopoulos, N. G., \& Rapp, A. (2012). A review of social media and implications for the sales process. Journal of Personal Selling \& Sales Management, 32(3), 305-316.

Bandura, A. (1993). Perceived self-efficacy in cognitive development and functioning. Educational Psychologist, 28(2), 117-148.

Baxendale, S., Macdonald, E. K., \& Wilson, H. N. (2015). The impact of different touch points on brand consideration. Journal of Retailing, 91(2), 235-253.

Bernoff, J., \& Li, C. (2008). Harnessing the power of the oh-so-social web. MIT Sloan Management Review, 49(3), 36-42.

Bitner, M. J., Booms, B. H., \& Tetreault, M. S. (1990). The service encounter: Diagnosing favorable and unfavorable incidents. The Journal of Marketing, 54(1), 71-84.

Boyd, D. M., \& Ellison, N. B. (2007). Social network sites: Definition, history, and scholarship. Journal of computer-mediated Communication, 13(1), 210-230.

Cova, B., \& Pace, S. (2006). Brand community of convenience products: New forms of customer empowerment-the case "my Nutella The Community". European Journal of Marketing, 40(9/10), 1087-1105.

Crawford, K. (2009). Following you: Disciplines of listening in social media. Continuum, 23(4), 525-535.

Deci, E., \& Ryan, R. M. (1985). Intrinsic motivation and self-determination in human behavior. Springer Science \& Business Media.

Deci, E. L., Eghrari, H., Patrick, B. C., \& Leone, D. R. (1994). Facilitating internalization: The self-determination theory perspective. Journal of Personality, 62(1), 119-142.

Deci, E. L., \& Ryan, R. M. (2000). The "what" and "why" of goal pursuits: Human needs and the self-determination of behavior. Psychological Inquiry, 11(4), 227-268.

Deutsch, M., \& Gerard, H. B. (1955). A study of normative and informational social influences upon individual judgment. The Journal of Abnormal and Social Psychology, 51(3), 629-636.

Eisenhardt, K. M. (1989). Building theories from case study research. Academy of Management Review, 14(4), 532-550.

Flavián, C., Ibáñez-Sánchez, S., \& Orús, C. (2019). The impact of virtual, augmented and mixed reality technologies on the customer experience. Journal of Business Research, $100,547-560$.

Fournier, S., \& Lee, L. (2009). Getting brand communities right. Harvard Business Review, 87(4), 105-111.

Gilgun, J. F. (2005). Qualitative research and family psychology. Journal of Family Psychology, 19(1), 40-50.

Greaves, F., Ramirez-Cano, D., Millett, C., Darzi, A., \& Donaldson, L. (2013). Harnessing the cloud of patient experience: Using social media to detect poor quality healthcare. BMJ Quality \& Safety, 22(3), 251-255.

Grolnick, W. S., \& Ryan, R. M. (1989). Parent styles associated with children's self-regulation and competence in school. Journal of Educational Psychology, 81(2), 143-154.

Hagel, J. (1999). Net gain: Expanding markets through virtual communities. Journal of Interactive Marketing, 13(1), 55-65.

Hansen, J. M., \& Levin, M. A. (2016). The effect of apathetic motivation on employees' intentions to use social media for businesses. Journal of Business Research, 69(12), 6058-6066.

Keating, P. J. (1995). A framework for classifying and evaluating the theoretical contributions of case research in management accounting. Journal of Management Accounting research, 7, 66-86.

Kim, H. S., \& Jin, B. (2006). Exploratory study of virtual communities of apparel retailers. Journal of Fashion Marketing and Management: An International Journal, 10(1), 41-55.

Krishen, A. S., Berezan, O., Agarwal, S., \& Kachroo, P. (2016). The generation of virtual needs: Recipes for satisfaction in social media networking. Journal of Business Research, 69(11), 5248-5254.

Lemon, K. N., \& Verhoef, P. C. (2016). Understanding customer experience throughout the customer journey. Journal of Marketing, 80(6), 69-96.

Liu, X., Shin, H., \& Burns, A. C. (2019). Examining the impact of luxury brand's social media marketing on customer engagement: Using big data analytics and natural language processing. Journal of Business Research. https://doi.org/10.1016/j.jbusres. 2019.04.042 in press.

Markland, D., Ryan, R. M., Tobin, V. J., \& Rollnick, S. (2005). Motivational interviewing and self-determination theory. Journal of Social and Clinical Psychology, 24(6), 811-831.

Marshall, M. N. (1996). Sampling for qualitative research. Family Practice, 13(6), $522-526$.

Miller, E. A., \& Pole, A. (2010). Diagnosis blog: Checking up on health blogs in the blogosphere. American Journal of Public Health, 100(8), 1514-1519.

Naslund, J. A., Aschbrenner, K. A., Kim, S. J., McHugo, G. J., Unützer, J., Bartels, S. J., \& Marsch, L. A. (2017). Health behavior models for informing digital technology interventions for individuals with mental illness. Psychiatric Rehabilitation Journal, 40(3), 325-335.

Peters, D., Calvo, R. A., \& Ryan, R. M. (2018). Designing for motivation, engagement and wellbeing in digital experience. Frontiers in Psychology, 9, 1-15.

Prahalad, C. K., \& Ramaswamy, V. (2004). Co-creation experiences: The next practice in value creation. Journal of Interactive Marketing, 18(3), 5-14.

Puccinelli, N. M., Goodstein, R. C., Grewal, D., Price, R., Raghubir, P., \& Stewart, D. (2009). Customer experience management in retailing: Understanding the buying process. Journal of Retailing, 85(1), 15-30.

Rains, S. A., \& Keating, D. M. (2011). The social dimension of blogging about health: Health blogging, social support, and well-being. Communication Monographs, 78(4), $511-534$.

Rook, D. W. (1987). The buying impulse. Journal of Consumer Research, 14(2), 189-199. Ryan, R. M., \& Deci, E. L. (Eds.), (2002). Self-determination theory and the facilitation of intrinsic motivation, social development, and well-being. American Psychologist, 55, 
$68-78$.

Ryan, R. M., \& Deci, E. L. (2017). Self-determination theory: Basic psychological needs in motivation, development, and wellness. Guilford Publications.

Seale, C., \& Silverman, D. (1997). Ensuring rigour in qualitative research. The European Journal of Public Health, 7(4), 379-384.

Thomke, S. H., \& von Hippel, E. (2002). Customers as innovators: A new way to create value. Harvard Business Review, 80, 74-81.

Underhill, P. (1999). Why we buy: The science of shopping. Random House Audio.

Verhoef, P. C., Lemon, K. N., Parasuraman, A., Roggeveen, A., Tsiros, M., \& Schlesinger, L. A. (2009). Customer experience creation: Determinants, dynamics and management strategies. Journal of Retailing, 85(1), 31-41.

von Hippel, E. (1994). Sticky information and the locus of problem solving: Implications for innovation. Management Science, 40, 429-439.

Yin, R. K. (1994). Case study research: Design and methods. London: Sage.
Ali Yakhlef is professor at Stockholm Business School, Stockholm University. His recent research interests include the role of embodied, spatial practices on the performance of everyday activities, such as working, learning, innovating and consuming. His work has appeared in Organization Studies, Research Policy, Time and Society, Consumer, Market and Culture, Marketing Theory, and Journal of Industrial Marketing, among others.

Fredrik Nordin is Professor of Business Administration at Stockholm Business School, Stockholm University. His research interests lie primarily in the area of business-tobusiness marketing in industrial and high-tech firms, focusing on how providers of technology products and services can help customers create value. He has previously published in, e.g., Industrial Marketing Management, Journal of Business Research, Journal of Business-to-Business Marketing, and Journal of Service Management 